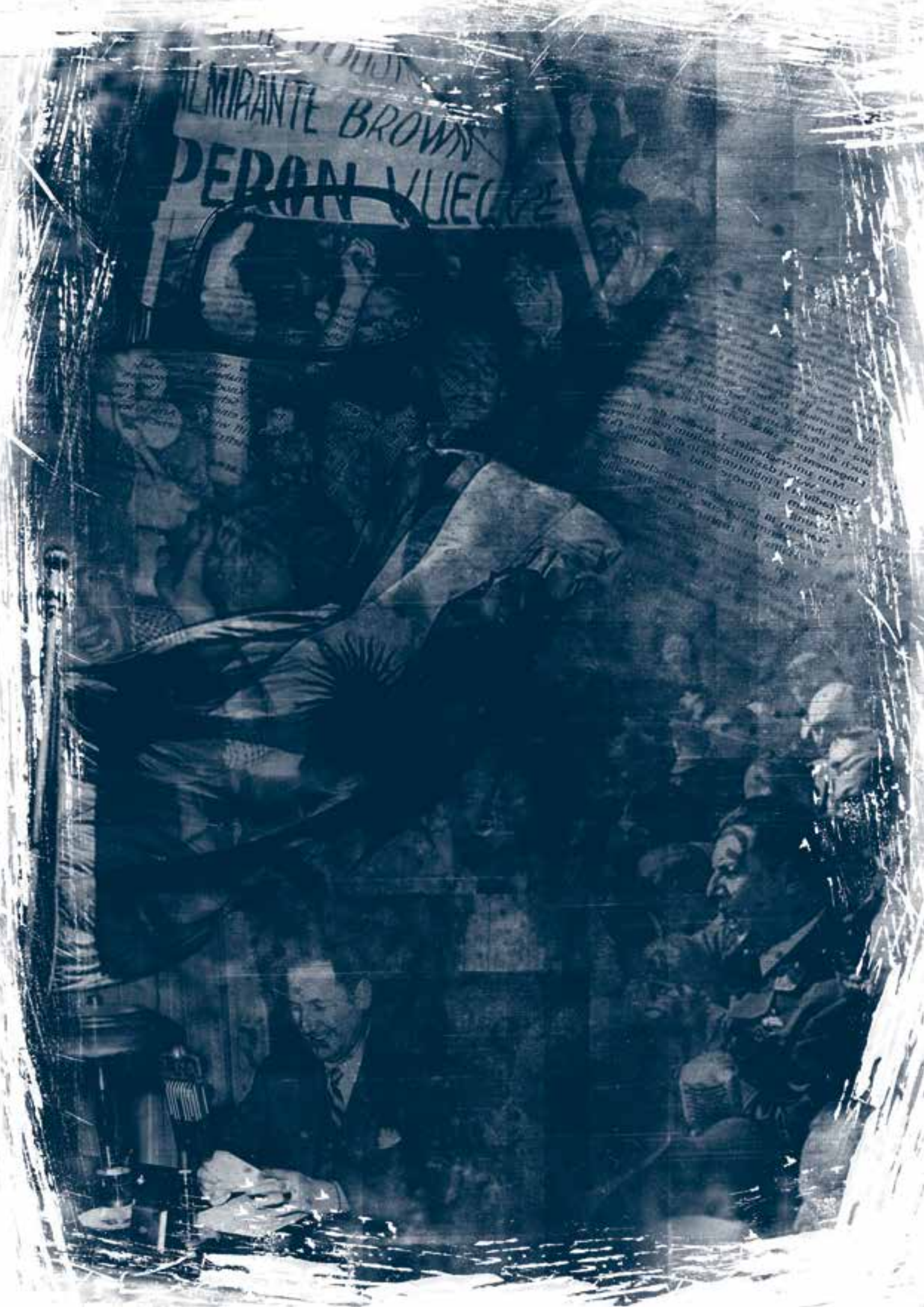




\title{
Peronismo y cultura de masas en la emergencia de los estudios en comunicación en la Argentina: itinerario de Jaime Rest
}

\author{
Peronism and mass culture in the emergence of communication \\ studies in Argentina: itinerary of Jaime Rest
}

DoI: $10.15213 /$ redes.n10.p185

MARIANO ZAROWSKY

\begin{abstract}
Jaime Rest published in 1965 in Revista de la Universidad of the National University of La Plata an article entitled "Alcances literarios en torno a una dicotomía cultural contemporánea”. This work, along with "Situación del arte en la era tecnológica" - published by Rest in 1961 in Revista de la Universidad de Buenos Aires - are considered by the argentine historiography of communication and culture studies as moments "precursors". According to this retrospective reading, the essays Rest promoted the emergence of an area of specialized knowledge: exposed the question of the links between art, culture and social history, putting in perspective the division between massive, high and popular culture that characterized the approach to literary criticism and sociology of the period and made available a series of readings and authors who will become some years later required references to deploy the question. In this article, in opposition to certain anachronism - this read retrospectively a disciplinary history from the perspective of a subsequent configuration, emphasizing the individual task of a "precursor" - we propose to put this "inaugural moment" at the crossroads of a collective movement and a series of institutional spaces and broader discursive formations. Indeed, in the essays of Jaime Rest the question for of mass culture status was linked to the question about the effects of the emergence of the masses in national life (read: the emergence of peronism) and was produced and circulated in formation and institutional spaces marked by the "developmentalism" climate of ideas and the academic reformism that ruled the university from 1956.
\end{abstract}

KEYWORDS: INTELLECTUAL HISTORY, STUDIES IN CULTURE AND

COMMUNICATION IN ARGENTINA, MASS CULTURE, PERONISM, JAIME REST

REDES.COM $\mathbf{N}^{\circ} 10 \mid 185$ 


\section{RESUMEN}

Jaime Rest publicó en 1965 en la Revista de la Universidad de la Universidad Nacional de La Plata un artículo titulado "Alcances literarios en torno a una dicotomía cultural contemporánea". Este trabajo, junto a "Situación del arte en la era tecnológica" - publicado por Rest en 1961 en la Revista de la Universidad de Buenos Aires - son considerados por la historiografía de los estudios en comunicación y cultura en la Argentina como momentos "precursores". Según esta lectura retrospectiva los ensayos de Rest promovieron la emergencia de una zona de saber especializado: instalaron la pregunta por los vínculos entre técnica, cultura e historia social, relativizando la división entre lo masivo, lo culto y lo popular que caracterizaba el abordaje de la crítica literaria y la sociología de la época y pusieron a disposición una serie de lecturas y autores que se convertirán algunos años después en referencias obligadas para desplegar el interrogante. En este artículo, intentando poner distancia de cierto anacronismo - que lee retrospectivamente una historia disciplinar bajo el prisma de una configuración posterior, enfatizando la tarea individual de un "precursor" - nos proponemos situar este "momento inaugural" en la encrucijada de un movimiento colectivo y de una serie de espacios institucionales y formaciones discursivas más amplias. En efecto, en los ensayos de Rest la pregunta por el estatuto de la cultura masiva se vinculaba al interrogante por los efectos de la irrupción de las masas en la vida nacional (leáse: la emergencia del peronismo) y se producía y circulaba en una serie de formaciones y espacios institucionales marcados por el clima desarrollista y el reformismo universitario que gobernó la universidad posperonista a partir de 1956.

PALABRAS CLAVE: HISTORIA INTELECTUAL, ESTUDIOS EN CULTURA Y COMMUNICACIÓN EN LA ARGENTINA, CULTURA DE MASAS, PERONISMO JAIME REST

\section{DEL PERONismo a LA CULTURA de MASAS}

Dando cuenta de la existencia de un debate en torno al estatuto de la cultura de masas ya instalado en el país hacía algunos años, Jaime Rest publicó en 1965 en la Revista de la Universidad de la Universidad Nacional de La Plata un artículo titulado "Alcances literarios en torno a una dicotomía cultural contemporánea". Este trabajo, junto a otro texto previo, "Situación del arte en la era tecnológica" - publicado por Rest en 1961 en la Revista de la Universidad 
de Buenos Aires - son considerados como "precursores" de los estudios culturales en el país, o, en otra posible modulación, como un "momento inaugural" de los estudios en cultura y comunicación en la Argentina. Según esta lectura retrospectiva los ensayos de Rest promovieron la emergencia en el país de una zona de saber especializado: instalaron la pregunta por los vínculos entre técnica, cultura e historia social, relativizando la división entre lo masivo, lo culto y lo popular que caracterizaba el abordaje de la crítica literaria y la sociología de la época y pusieron a disposición una serie de lecturas y autores, de Walter Benjamin a Richard Hoggart, de Raymond Williams a Roland Barthes, entre otros, que se convertirán algunos años después en referencias obligadas para desplegar el interrogante. ${ }^{1}$

En este artículo, a distancia de cierto anacronismo - que lee retrospectivamente una historia disciplinar bajo el prisma de una configuración posterior, enfatizando la tarea individual de un "precursor" - nos proponemos situar este "momento inaugural" en la encrucijada de un movimiento colectivo, de un espacio institucional y una formación discursiva más amplia. En el espacio de interlocución en el que se ubicaban los ensayos de Rest la pregunta por el estatuto de la cultura masiva se vinculaba al interrogante por los efectos de la irrupción de las masas en la vida nacional y, por ende, se anudaba con una serie de preguntas por entonces ineludibles para quien quisiera participar de la vida intelectual. A saber: ¿qué hacer con las masas?; o de otro modo: ¿qué hacer con el peronismo? Si Cuatro hipótesis sobre la Argentina (un trabajo de Rest inmediatamente previo editado en Bahía Blanca por la Universidad Nacional del Sur en 1960) se ubica claramente en la tradición del ensayo de interpretación de la realidad nacional, "Situación del arte en la era tecnológica" y "Alcances literarios en torno a una dicotomía cultural contemporánea", publicados en las revistas de las universidades de Buenos Aires y La Plata, por entonces vehículos y expresiones del clima reformista que se desplegaba en estos espacios (el segundo, además, se reeditaría a instancias de Aníbal Ford en 1967 como Literatura y cultura de masas en el Centro Editor de América Latina, donde alcanzará una amplia difusión) se colocan en un

1. Jorge Rivera (1987: 71) señala que, con esos ensayos, Jaime Rest fue un "precursor del análisis de la cultura de masas" en el país. Aníbal Ford (2001 [1994]: 19), por su parte, escribe que "Jaime Rest fue el maestro de muchos de nosotros. Vio con claridad las relaciones entre cultura, los medios, las tecnologías, la política, la historia social (...) Fue el creador de los estudios culturales en la Argentina”. En esta línea y en referencia a la serie de autores (Barthes, Williams, Hoggart, etc.) que Rest citaba de sus ediciones originales, Víctor Pesce (2006:14) escribe que "también en eso Rest fue un adelantado". En la misma línea, véase también Barduil (1999: 183), Alabarces (2006) y Crespi (2010: 12). 
registro híbrido que incorpora elementos de una escritura científico-académica que pretende desde esta nueva colocación intelectual involucrarse en los debates en torno a los destinos nacionales o, más precisamente, acerca de los camino hacia el desarrollo. En el espacio que media entre uno y otro tipo de intervención se pueden delimitar los contornos político-intelectuales y las coordenadas institucionales en las que emergió la problemática de la cultura de masas y el estudio de los medios de comunicación en el país.

En efecto, Cuatro hipótesis de la Argentina (Rest, 2010 [1960]) ${ }^{2}$ se inscribía claramente en la tradición del ensayo argentino de interpretación de la realidad nacional y, ya desde el comienzo, revisaba algunas de sus figuras emblemáticas - Domingo Faustino Sarmiento, Eduardo Mallea, Ezequiel Martínez Estrada - retomando uno de sus tópicos centrales: el diagnóstico común en torno a la estructura bipolar que explicaba la causa de la crisis recurrente del país, o, de otro modo, la contradicción profunda entre dos argentinas antagónicas.

Por supuesto, a Rest no lo impulsaba un ánimo historiográfico. No es difícil reconocer en su lectura de Sarmiento y en la filiación que asumía con su obra un programa de intervención intelectual para su presente y un intento por tomar la palabra en el debate de la hora en torno a los hechos que dividían al país. ${ }^{3}$ Tampoco se trataba de un gesto aislado: hacia finales de los años cincuenta se puede comprobar en una franja de la intelectualidad argentina

2. Rest, graduado en Letras por la Universidad de Buenos Aires en 1953, profesor asociado de literatura inglesa y norteamericana entre 1956 y 1963 en la Facultad de Filosofía y Letras (compartía la tarea con Jorge Luis Borges) escribía por entonces en revistas vinculadas a la círculos culturales de la elite liberal antiperonista, como Imago Mundi, dirigida por José Luis Romero, y en la más veterana revista Sur, entre otras. Cuatro hipótesis de la Argentina era su primer texto editado de manera independiente. Ver Crespi (2010: 31). Cito de aquí en adelante una reedición publicada en 2010 (Rest, 2010 [1960]).

3. El propósito de Sarmiento - escribía - había sido revelar el carácter dominante de la sociedad argentina mediante un estudio general de las fuerzas que incidieron en su constitución para elaborar una "hipótesis de acción" (pp. 36-37). De un lado ubicaba las fuerzas inorgánicas, autocráticas, pero dinámicas; del otro, los núcleos liberales doctrinarios, la ortodoxia teórica. Según Rest, la perspectiva extraordinaria del Facundo había consistido en encarar por primera vez este problema, "en buscar una fórmula que explique la división y que establezca las bases de un reencuentro nacional” (p. 44). Sarmiento había comprendido que era necesario definir la situación del país, a fin de deslindar las fuerzas en pugna y de explorar los medios que permitiesen una resolución del conflicto que "había engendrado un clima de caos e incoherencia” (p. 44). Superaba así a la minoría ilustrada al tener en cuenta, con bases científicas, la naturaleza de la realidad nacional; a partir de ahí podía proponer los medios para transformar y superar las antinomias, dejando de lado fórmulas ideales, dogmáticas. 
un retorno a la problemática de la ensayística de los años treinta, esto es, de una vuelta a una literatura que, retomando a su vez textos fundamentales del siglo xIx, había diagnosticado una profunda crisis de identidad nacional (Terán, 1991: 138-139; Neiburg, 1998: 98-99; Saítta, 2004). Las causas de este regreso eran inequívocas: el derrocamiento de Perón había puesto en el centro del debate todas las cuestiones y planos de la existencia nacional y toda la discusión intelectual en torno al significado del peronismo estaría regida por esta problemática; un ánimo de examen histórico iba ligado a la convicción de que se asistía a un momento que era a la vez de clausura y de inauguración. $\mathrm{O}$, de otro modo: se asistía a la certeza de que explicar el peronismo era sinónimo de explicar la Argentina (Altamirano, 2011 [2001]: 217). La cuestión de fondo, puesto que las masas ya no estarían dispuestas a retrotraer su situación hacia la de diez años atrás, ni quienes habían dado un golpe de Estado permitirían el retorno de su líder, se organizaba en torno a una apremiante pregunta de orden político-programático. A saber: ¿qué hacer con las masas? $\mathrm{O}$, de otro modo: ¿cuál sería la fórmula del posperonismo?

En Cuatro hipótesis de la Argentina las referencias que hacía Rest al peronismo y la toma de posición respecto a éste, como era entonces obligado, eran explícitas. ${ }^{4}$ Se puede enmarcar en la visión de una franja intelectual de tradición liberal que, diferenciándose de las posiciones más dogmáticas e intolerantes, buscaba por entonces una comprensión de las condiciones de su existencia al mismo tiempo que condenaba sin matices sus formas de manifestación. Esta perspectiva habilitaba, así, posibles alternativas de desperonización.

Ahora bien, uno de los elementos que singulariza el trabajo de Rest en relación con la ensayística de la época (incluso en relación con la de sus contemporáneos contornistas ${ }^{5}$ ) es que en sus páginas se mezclaban rasgos típicos del

4. Escribía: "La perspectiva histórica nos pone de parte de las minorías ilustradas; representa, para nuestro juicio el porvenir de la Argentina: sólo la fe liberal que las inspiraba pudo ser capaz de construir un país, extrayendo del desierto, la adversidad y el olvido (p. 43). Más adelante, luego de ensayar una lectura histórica que pasaba por la ley Sáenz Peña, el yrigoyenismo, el golpe de 1930 y la restauración conservadora que había agudizado la inestabilidad social, escribía que "todo parecía dispuesto para que el primer aventurero afortunado que supiera captarse el favor de las masas se adueñase del poder". Así, luego de trece años de ficción democrática y de "fraude patriótico" — anotaba Rest - se produjo el cataclismo (p. 67). Más adelante Rest refiere a un trabajo de Gino Germani como un texto sobre las "circunstancias que engendraron nuestro reciente interludio tiránico" (p. 76). Todos los subrayados me pertenecen.

5. Por cierto, en relación con la cuestión peronista Rest se diferenciaba de los contornistas denunciando que en su actitud parricida subyacía un mero "gesto de rebeldía”, una impostura contra la vieja generación 
ensayo con elementos provenientes de los "nuevos saberes" sociales - más precisamente, la historia social y la sociología científica - que despuntaban por entonces en el país de la mano de José Luis Romero y Gino Germani. Estos saberes se presentaban como una nueva voz de autoridad para pronunciarse sobre la historia y los destinos de la nación, proponiendo un punto de vista que se legitimaba por su condición de saber científico y objetivo. Como se ha demostrado in extenso, tendrán notable éxito en la reconfiguración de las posiciones de prestigio en un campo intelectual y en un mundo universitario que se reorganizaban aceleradamente a partir de 1955 (Neiburg, 1998: 89-92; Altamirano 2011 [2001]: 238; Blanco, 2006).

En efecto, aunque no abandonara la forma del ensayo y algunos elementos claves del género (el uso de la primera persona remite a un nombre propio que garantiza la verdad de una interpretación ${ }^{6}$ ), en Cuatro hipótesis sobre la Argentina Rest destacaba entre las investigaciones sobre historia y estructura social dos trabajos que buscaban una "elucidación de la realidad argentina actual con objetividad y espíritu científico". Por un lado, Argentina, imágenes y perspectivas (1956) de José Luis Romero; por otro, "La integración de las masas a la vida política y el totalitarismo", de Gino Germani.7 Rest recorría ampliamente este análisis del sociólogo italiano que se volvería un clásico en la interpretación sobre el peronismo (contra la que se medirán una y otra vez en los años siguientes las distintas variantes de la sociología argentina y todas las tradiciones intelectuales que discutirían la cuestión) haciendo suyo el intento de pensar, contra el antiperonismo intelectual más dogmático, las razones histórico-sociales profundas que explicaban su emergencia y, sobre todo, aquello que había de razonable en el apoyo que obtuvo por parte de las masas. Rest retomaba entonces uno de los tópicos centrales del planteo de Germani: prescribía la incorporación de las mayorías a la vida política como modo de resolver la crisis general de la cual el peronismo era una manifestación particular, aquella que desencadenaba el pasaje de la sociedad tradicional a la sociedad

intelectual. Rest tomaba el partido de la vieja generación.

6. Sylvia Saítta (2004) repasa los rasgos del género en su estudio sobre el lugar del ensayo de interpretación de la realidad nacional en el contexto posperonista y en el marco de la reconfiguración del campo intelectual y académico de los años sesenta.

7. En rigor Rest citaba Política e massa (Minas Gerais, Estudos Sociais e Políticos, 1960), una versión brasileña de Política y sociedad en una época de transición (1962) que se había publicado antes que la edición argentina y que, al igual que la edición nacional, incluía el ensayo "La integración de las masas a la vida política y el totalitarismo", publicado originalmente en 1956 por Germani en la revista Cursos $y$ Conferencias. Agradezco a Alejandro Blanco su disposición para ayudarme a elucidar esta cuestión. 
de masas. Disociar el contenido - la experiencia de participación de las masas en la vida social - de su forma política efectiva - el peronismo - y reunir ese contenido con otra forma, resumía la fórmula de desperonización que proponía Germani y que, en su esquema esencial - separar forma y contenido - podía detectarse en todas las posiciones para las cuales la experiencia de los diez años peronistas no había sido un hecho compactamente negativo (Altamirano, 2011 [2001]: 240). ${ }^{8}$

El relieve que toma en el ensayo de Rest el artículo de Germani es central en nuestra perspectiva y amerita que nos detengamos en éste. Como se ha señalado en varias oportunidades, en "La integración de las masas a la vida política y el totalitarismo" se puede leer una huella clara del modo en que la aparición de la problemática de la sociedad de masas que signó la consolidación de la sociología científica en el país a partir de 1955 estuvo íntimamente ligada a la reflexión sobre el hecho peronista. En este y otros trabajos Germani construía la legitimidad de una nueva posición intelectual y de un nuevo punto de vista que, descentrándose de las posiciones clásicas del antiperonismo, despuntaba por entonces en amplias franjas intelectuales y señalaba la necesidad de la integración de las masas a la vida nacional; ponía de relieve el hecho ineludible de que "vivimos en una sociedad de masas" y que, en este tipo de sociedad, éstas "ya no están excluidas del ejercicio del poder político. O por lo menos ya no quieren estarlo". De allí que - sintetizaba y adelantaba su fórmula de desperonización - "de algún modo hay que contar con ellas para gobernar" (2006 [1956]: 203).

El sociólogo planteaba tres condiciones para que la democracia de minorías se transformara en una efectiva democracia en la que todos pudieran participar: mayor justicia en la distribución económica; mayor justicia distributiva también en el orden cultural; y, por último, pleno ejercicio de la democracia y la libertad política (p. 204). Germani alcanzaba a enunciar también (aunque no lo desarrollaría in extenso en su artículo, puesto que se ocuparía sobre todo de la cuestión política) una serie de elementos vinculados a la dimensión cultural como condición del establecimiento de una democracia de masas. Escribía:

una justicia distributiva debe reinar en el orden cultural. En la actualidad, la mayoría está excluida de los grandes valores de la cultura. En lo intelectual y en lo estético, reina la misma escisión

8. Aunque dedicaba un lugar importante a la posición de Germani y a su caracterización del peronismo, Rest se apoyaba para su formulación en un extenso comentario de El desarraigado argentino, un ensayo de Julio Mafud publicado poco tiempo antes. 
que en el orden político: una cultura, o si se quiere la 'cultura' para la minorías, y las formas comercializadas de la diversión de masa para todo el resto. Existen los medios técnicos y también se conocen las formas organizativas necesarias para asegurar un igual acceso a los productos de la cultura; de manera que no es utópico pensar que también esta condición puede lograrse si se alcanza la primera condición (p. 204).

No es exagerado decir que este breve fragmento expresa una de las posiciones más extendidas entonces respecto al estatuto de la cultura de masas. En primer lugar, se hace referencia a la existencia de una escisión entre una cultura de elite - que es visualizada como sinónimo de la cultura - y una cultura de masas, vinculada al comercio y la diversión que no era otra cosa que su degradación. No obstante, en segundo lugar, se sostiene una caracterización optimista en torno al potencial de la cultura de masas que se deriva de la posibilidad de practicar una acción pedagógica democratizadora que, dados los medios técnicos existentes, podría acercar la cultura (de elite) a las masas si se encara una política de distribución cultural.

Como veremos, la intervención pionera de Jaime Rest en el debate sobre la cultura de masas está en sintonía con el trabajo de Gino Germani y su caracterización del peronismo como manifestación de las tensiones inherentes al pasaje de la sociedad tradicional a la sociedad moderna. Lo notables es que si en Cuatro hipótesis de la Argentina (1960) la lectura del peronismo era explícita y estaba soldada a un interrogante que le daba sentido - a saber: qué hacer con las masas - en los ensayos inmediatamente posteriores de Rest $(1961,1965)$ la cuestión aparecerá flagrantemente escindida y la cuestión del peronismo elidida: la pregunta en torno a qué hacer con las masas (y por entonces, por más que les pesara a los proscriptores, las masas llevaban inequívocamente en su frente su propio calificativo: eran peronistas) reaparecerá transfigurada en otra que la va a contener soterradamente y de manera algo despolitizada: qué hacer con la cultura de masas.

\section{DEL PERONISMO A LA CULTURA DE MASAS II (EXCURSUS SObRe JOSÉ MIGUENS)}

Para argumentar en torno a esta exclusión que rodea la emergencia de la problemática de la cultura de masas me permito hacer un rodeo en relación con el itinerario de Rest y remitir brevemente a un ensayo sociológico contemporáneo a sus trabajos. Me refiero al estudio del sociólogo José Enrique 
Miguens 9 publicado en 1961 por la tradicional editora del grupo Sur en un volumen colectivo: Argentina 1930-1961. ${ }^{10}$

Como su título deja entrever, el trabajo se proponía la ambiciosa tarea de examinar todas las dimensiones de la vida nacional en el período. A pesar de los eufemismos que proliferan en sus páginas no es difícil identificar allí un sentimiento de estupor frente al período 1946-1955, un ánimo de búsqueda de categorías para comprender el peronismo y, dada su caída, delinear alternativas de superación. ${ }^{11}$ Una de las secciones, bastante voluminosa, se dedicaba a la "cultura de masas" e incluía trabajos sobre radio y televisión, cine, periodismo y deportes. El capítulo de José Miguens abría la sección y ofrecía una lectura sociológica de la problemática que mezclaba referencias y citas de José Ortega y Gasset, la sociología funcionalista, la teoría de la información de base ingenieril y la psicología de la conducta. Revisar mínimamente sus ideas fuerza nos permitirá situar el marco de interlocución en el que se ubicaba de manera diferencial la intervención de Rest, al mismo tiempo que poner de relieve el modo en que la apropiación sociológica local de la cuestión de la cultura de masas se entreveraba con la cuestión del peronismo y, de algún modo, la iba a solapar.

¿Qué era la masa? ¿Cuál era el estatuto de su cultura? Miguens (1961: 330) definía a la "masa" como un agrupamiento colectivo elemental y espontáneo compuesto por individuos de extracción social heterogénea, aislados y sin interacción entre sí, que sufrían de modo "pasivo" y "receptivo" una fuente común de estímulos. Frente a estas masas estaba el "foco", del cual emergían los signos o señales, que eran "los excitantes destinados a provocar algún

9. Abogado de formación con un posgrado en Sociología en Harvard (1944-1945), Miguens fue uno de los referentes de la institucionalización de la sociología en la Argentina, fundador y director del departamento de sociología de la Universidad Católica Argentina, en 1959. Sobre la trayectoria intelectual de Miguens ver Aramburu, Giorgi (2013).

10. Llama la atención que en su historia de la investigación sobre comunicación en la Argentina, al señalar la aparición en el país de la cuestión de la cultura de masas hacia inicios de los años sesenta, Jorge Rivera no vincule esta emergencia con la conmoción que produjo la caída del peronismo y los debates que se dieron en el mundo intelectual en torno a su significación. La ausencia es notable puesto que Rivera (1987: 30-31) recupera como "pionero" en el desarrollo de la problemática en el país este trabajo de José Miguens.

11. En el prólogo al volumen colectivo se puede leer la siguiente y elocuente caracterización del período iniciado en 1930: "Nuestro acontecer desde ese año compone una caída, un enajenamiento y un despertar difícil que nos ha dejado sin saber ya bien quiénes somos. Vagamente recordamos, sí, que se nos ha dicho que éramos un país joven, un país rico, un país de promesas...” (AA.vv., 1961: 7). 
comportamiento de la masa". De un lado entonces estaban "los emisores de estímulos" y del otro, "los destinatarios o receptores". Conectando a ambos términos y contribuyendo también como elemento a definir la situación estructural que es la masa, el sociólogo situaba la red de "canales de comunicación que transmiten los referidos signos del lado activo de la situación al lado pasivo, los modos masivos de expresión y los medios masivos de reproducción de éstos". Como se puede anticipar de esta caracterización, la evaluación que hacía Miguens del estatuto de la cultura de masas era lapidario. ${ }^{12}$

El sociólogo combinaba esta serie de definiciones conceptuales con un análisis histórico de la emergencia de la cultura de masas en el país que no disimulaba su enlace con su apreciación del peronismo. La aparición de este fenómeno político coincidía con el tránsito y la configuración de la "situación de masa" en el país que se había comenzado a producir a partir de una serie de cambios económicos y demográficos que socavaron el liderazgo político-cultural de los grupos sociales de referencia tradicionales y promovieron una situación de "disponibilidad" de la masa de migrantes internos y externos para la recepción de un liderazgo de nuevo tipo que terminaría por consolidarla (pp. 341-346). En términos generales su balance del período era poco favorable a los cambios que se habían sucedido en el país. ${ }^{13}$

Lo cierto es que en el trabajo de Miguens (particular híbrido entre el ensayo valorativo y la emergente sociología científica que, vía confrontación con la empiria y el análisis de la estructura social, buscaba alzar una nueva

12. La masa - escribía - "surge del sujeto colectivo emisor que hace de foco. Se llama de masas en cuanto está elaborada para ese mercado, distribuida por los medios masivos de comunicación y consumida de la manera superficial y pasiva que es propia del sujeto colectivo receptor. Aunque parezca también paradójico, las masas no producen la cultura de masas sino que la reciben, pero por su mera presencia y modo de ser, junto con el modo de ser del foco y del sistema de comunicación, condicionan la producción de cualquier manifestación cultural exterior y la convierten en cultitura [sic] 'enlatada', como la llaman algunos" (p. 332).

13. La evaluación que hacía Miguens del proceso migratorio y de sus consecuencias político-culturales es elocuente: comparaba el fenómeno con la invasión de los recién considerados ciudadanos a partir del edicto de Caracalla, en el Bajo Imperio Romano. "En la invasión a la capital — escribía —, ocurre lo mismo. Los recién venidos ocupan los aledaños culturales, adonde menos llega la fuerza integradora de la cultura urbana" (p. 343). Finalmente, concluía que entre 1946 y 1955 se había desarrollado sistemática e implacablemente la tentativa gubernamental de obtener, mediante el manejo de la prensa, los diarios y las revistas, "el control total del foco, con el fin de dirigir las grandes multitudes del proletariado urbano que se estaban cristalizando en la situación masiva y establecer una verdadera estructura social de masa" (p. 346). 
voz de autoridad en el debate sobre el peronismo) la búsqueda de una fórmula de desperonización se enunciaba en torno a la pregunta respecto a qué hacer no con las masas, en general, sino con la cultura de masas. ${ }^{14}$ Si por entonces para Gino Germani la sociedad de masas era un hecho irreversible y, sobre todo, tenía un potencial democrático, para Miguens, por el contrario, estaba pendiente el encuentro de una solución a la cuestión fundamental. A saber: "¿cómo podemos salir de la sociedad de masas y, por lo tanto, de su cultura?" (p. 350). La pregunta, así formulada, mostraba una opción conservadora que no habilitaba líneas claras de acción.

\section{DE LAS MASAS a LO POPUlar}

Por entonces la perspectiva de Jaime Rest en torno a la cuestión tendrá elementos en común pero también diferencias notables en relación con la posición de Miguens. También notaremos en "Situación del arte en la era tecnológica" (1961) algunos desplazamientos con respecto a su propio ensayo, Cuatro hipótesis de la Argentina. La modalidad de enunciación (de la primera a la tercera persona), la política de citas (del ensayo nacional al predominio de referencias de la sociología europea y norteamericana), en suma, la variación general del género, parecían adecuarse al nuevo marco institucional donde se publicaba el trabajo: la Revista de la Universidad de Buenos Aires, Quinta época, dirigida por José Luis Romero, por entonces Decano de la Facultad de Filosofía y Letras.

El proceso de cambio que se vivía en la universidad argentina desde 1955 era vertiginoso. Hacia 1961, en el contexto de la reorganización posperonista y frustradas las expectativas iniciales que había generado el frondicismo en un sector de la intelectualidad progresista, el espacio modernizador, reformista y liberal que dirigía la Universidad de Buenos Aires se imaginaba a sí mismo como un actor en condiciones de realizar un verdadero experimento institucional, consistente en identificar a la universidad con una empresa político-cultural implicada en los debates acerca del destino de la nación.

\footnotetext{
14. Sobre la cuestión, que Miguens evaluaba como la "fundamental de nuestro tiempo" (p. 335) reinaba en la literatura sobre el tema cierta confusión que hacía errar la mayoría de las actitudes y las soluciones ensayadas o propuestas: éstas iban desde la evasión, el enojo (donde Miguens incluía a la crítica marxista de Adorno, Horkheimer o Fromm, entre otros) a la aceptación de la cultura de masas que promovían capitalistas, soviéticos y los “comunismos subdesarrollados” (léase: el peronismo). En esta última categoría optimista entraban también los deseos de algunos "socialistas y liberales de corregir a las masas, dándole en lugar de la usual papilla cultural, buenos productos”, escribía (p. 339).
} 
Para ello su misión sería generar y difundir una serie de saberes expertos y de vocación humanista. Uno de los referentes de este espacio, José Luis Romero, a partir de su llegada a la dirección de RUBA, en 1960, modificaría el perfil de la publicación, incorporando secciones nuevas y, sobre todo, estructurando cada volumen alrededor de un tema central. En líneas generales, este perfil marcaba una ruptura con un tipo de revista fragmentaria que solicitaba a sus lectores desde su especificidad disciplinar, para pasar a una interpelación que, como anota Claudio Suasnábar (2004: 51), si bien se dirigía a actores académicos, lo hacía "en tanto intelectuales públicos, que reivindican su legitimidad para la intervención en los destinos nacionales".

El primer número del sexto año de RUBA (enero-marzo de 1961) estaba dedicado a la cuestión del desarrollo y a las alternativas posibles que suscitaba: cambio gradual o revolución. El segundo (abril-junio de 1961) - aquel en el que Rest publicaba su artículo - abordaba las relaciones entre ciencia, técnica y cultura. La continuidad entre una y otra temática ${ }^{15}$ nos enmarca el artículo de Rest y permite leer su posición con respecto a la cultura de masas como un verdadero programa de intervención modernizante. Pues, en líneas generales, tal como escribe Altamirano (2007 [2001]: 74) el optimismo desarrollista "estaba en el aire y remitía a un espíritu generalizado". Este clima de ideas se desplegó con mayor intensidad en una franja universitaria que gozaba de una libertad y estabilidad que, si bien alimentó diferentes y prolíficas figuras intelectuales, al mismo tiempo contrastaba con un espacio social que, de conjunto, estaba marcado por la exclusión política y la represión.

Tal vez este paradojal marco de optimismo desplegado sobre un fondo de proscripción nos permita situar la flagrante ausencia en "Situación del arte en la era tecnológica" (a diferencia del propio ensayo inmediatamente anterior de Rest) de cualquier alusión que permita anudar la problemática de la cultura de masas con la cuestión del peronismo. No obstante, si esta omisión invisibilizaba la identidad política de las masas, no por ello disimulaba su presencia inquietante en la escena cultural. La evaluación que hacía Rest de aquellas no era ajena a los prejuicios de clase ni a algunos de los tópicos antiperonistas que había deslizado en su ensayo anterior. Así, en su nuevo

15. Esta continuidad se puede seguir en los diversos artículos que componen los dos números. En el primero, a los artículos de Jorge Graciarena y Aníbal Pinto o Torcuato Di Tella, que abordaban aspectos económicos o sociales del desarrollo, los seguían los de León Rozitchner o Risieri Frondizi, que anudaban la cuestión del desarrollo con problemáticas vinculadas a la cultura y a la universidad. En el segundo número la relación entre ciencia, técnica y cultura era abordada, entre otros, por Jaime Rest, Manuel Sadosky, Robert Oppenheimer y Gregorio Klimovsky. 
trabajo, no dudaba en señalar que, entre los riesgos que entrañaba la difusión mecánica de la producción cultural, "la amenaza más grave" era la adulación de un "gusto totalmente indiscriminado y sin exigencias" que promovía una "táctica demagógica que propiciaba la consolidación de una actitud irracional, destinada en última instancia a fortalecer ese natural instinto de rebaño, cuyos nocivos efectos sociales suelen manifestarse en la "captación de masas". Este fenómeno - escribía - hacía "posible la instauración de regímenes totalitarios" (2006 [1961]: 61-62).

De todos modos, más allá de esta (no tan) elíptica alusión, la cuestión peronista aparecía de manera general aquí soterrada, o mejor dicho, desplazada por otra que, como un nuevo fantasma amenazante, tomaba su relevo: la cultura de masas. Dos observaciones que a modo impresionista ofrecía Rest en torno al modo en que las masas se vinculaban con ciertos medios técnicos de reproducción cultural son elocuentes de su posición frente a aquella. Escribe con respecto a la popularización de la radio a transistores:

Para ciertos estratos de la población urbana, se ha convertido en elemento indispensable, al punto de que sus integrantes no pueden salir a la calle sin el equipo a cuestas. Pareciera, inclusive, que el actual individuo medio carece de capacidad para comprender lo que observa por sí solo, sin que le ofrezcan al mismo tiempo una explicación del espectáculo que se adecue a su mentalidad. Ello suele observarse, por ejemplo, en los partidos de fútbol, entre cuya concurrencia no resulta inusitado hallar quienes escuchan aquello mismo que están contemplando (p. 36).

Con respecto al cine, Rest relataba su impresión en torno a la exhibición en Buenos Aires del film inglés Conspiracy of Hearts (1960) cuya trama, ubicada en Italia durante la Segunda Guerra Mundial, describía las peripecias de un grupo de monjas católicas que trataba de rescatar niños judíos de un campo de concentración nazi. Según la percepción de Rest, la tesis humanitaria que proponía el film no era percibida por los espectadores, quienes, en lugar de tender a generalizar el mensaje, "esquematizaban las principales figuras de acuerdo con las habituales convenciones cinematográficas". La escena, escribía:

que contaba con más estruendosa aprobación popular era aquella en que el oficial italiano y su tropa daban muerte a los militares alemanes que habían dispuesto el fusilamiento de varias 
monjas; este ruidoso beneplácito demuestra que la concurrencia se había sumergido afectivamente en la situación misma a tal punto que casi nadie se preocupó en tener presente el concepto misericordioso propiciado a lo largo de la película (pp. 62-63. El subrayado me pertenece).

Estas consideraciones permiten leer sin matices la presencia en este trabajo de Rest de un punto de vista legitimista. ${ }^{16}$ Por un lado, porque el tipo de fuentes en que se basa y el tono de su descripción revela su completa exterioridad respecto a la vida cultural de las masas y a sus manifestaciones; por otro, y sobre todo, porque las evalúa en términos de absoluta negatividad, por ejemplo, cuando considera el uso masivo de la radio a transistores como signo de una actitud contemplativa frente a la cultura; o cuando deduce la falta de juicio de las masas del bullicio irreflexivo que - al parecer del crítico - despertaban los momentos culminantes del film que comentaba. En este sentido, si, como se ha señalado (Rivera, 1987: 31-32; Pesce, 2006: 14), la posición que Rest exhibía en este trabajo fue pionera en el país en su matización de las tesis más pesimistas sobre el carácter y el porvenir de la cultura de masas, conviene decir aquí que no lo era porque reconociera elementos activos o progresivos en éstas (como veremos, Rest variará su posición notablemente en su segundo trabajo sobre la cuestión, de 1965), sino porque evaluaba que la amenaza era mucho menor que lo que suponían algunos de sus críticos. Para justificar esta idea, Rest ofrecía argumentos por demás elocuentes. La "producción mediocre - escribía - incide de manera casi exclusiva en ciertas clases que sólo fueron alfabetizadas en épocas recientes y que en el pasado no contaron con beneficios culturales o artísticos" ( $p$. 63). De allí que, si se aceptaba este razonamiento, no sería posible hablar de "decadencia del gusto estético", ya que la industria de difusión cultural en sus aspectos más desacreditados "no perjudicaría a las personas realmente cultivadas, sino que se propondría satisfacer la vulgaridad de aquella masa de población que recibió apenas una educación muy elemental" (pp. 63-64).

16. Grignon y Passeron (1991) utilizan el concepto para referir al modo en que cierto tipo de sociología aborda la cuestión de la cultura popular. Si bien reconocen como aspecto positivo el hecho de que ésta identifique las relaciones de dominación en las que se inserta la producción simbólica de los sectores populares, al mismo tiempo observan que desde este enfoque la cultura dominante sería la única que tendría la responsabilidad de definir cuáles son las representaciones culturales válidas para todas las culturas. No existiría una cultura más allá de la cultura legítima o dominante y la cultura popular sería una suerte de no-cultura, caracterizada por la ausencia de rasgos propios. 
En la misma línea, que se hubiera tornado "conspicua la producción más infame" no permitía suponer que las creaciones "inferiores" estuvieran desplazando a las "manifestaciones artísticas superiores". Por el contrario, lejos de producir una degradación de la calidad estética (y esta es una hipótesis fuerte del texto que sí suponía una novedad considerable y un desafío a las posiciones de la crítica más conservadora) el contacto de las artes más elevadas con los nuevos medios de difusión mecánicos permitía el despliegue de innovaciones estéticas: en términos formales o temáticos; en la actitud del artista con respecto a sus posibilidades creadoras; o en el desarrollo de procedimientos narrativos de nuevo tipo (pp. 68-72).

No obstante, en la perspectiva de Rest estas posibilidades se desplegaban siempre en los ámbitos de la cultura "superior": de allí que el problema no estuviera en los "vehículos difusores mismos" sino en "los individuos pertenecientes a los sectores menos cultivados, a quienes se ha dado una instrucción insuficiente que los habilita para leer pero no para ejercer el más mínimo sentido crítico" (p. 65). Para las masas, en consecuencia, quedaba la posibilidad de la acción reformadora. En sí mismos el cine, la radio, la televisión, la prensa, no eran peligrosos ni dejaban de serlo; eran "meros instrumentos" cuyos efectos positivos o negativos dependían, exclusivamente, del empleo que se les diera: "la cuestión consiste en que son sumamente eficaces, sea cual fuere el objetivo propuesto, y resultan, por ende, útiles herramientas para quienes desean orientar la opinión pública de buena o mala fe, con fanatismos o espíritu comprensivo", concluía Rest. Lo que se jugaba, en definitiva, era la posibilidad de desplegar una acción pedagógica hacia las masas. Se basaba en la creencia de que una adecuada socialización de los mecanismos difusores podía conducir a "una acción pedagógica más racional, planificada con el propósito de comprometer al público de todas las edades y sectores en un vasto y ambicioso proyecto cuya aspiración última sería elevar el nivel cultural de la colectividad en su índice medio" (p. 89).

Estos planteos dan cuenta de la expectativa de Rest en torno a la posibilidad de planificar y orientar el desarrollo de la cultura de masas en el país. En su apuesta se puede leer también la promoción de una imagen del crítico cultural que se desplegaba en el contorno de un espacio intelectual reformista y liberal que imaginaba para la universidad un papel protagónico y rector de los procesos de cambio. Esta particular figura del compromiso reunía la vocación intelectual humanista - preocupada por la comprensión del hombre histórico y la búsqueda de una justificación externa del conocimiento - con el deseo de satisfacer los imperativos de las nue- 
vas ciencias del hombre, orientadas hacia la actualización teórica y el rigor metodológico. ${ }^{17}$

La escritura de Rest nos da otra pauta de los modos en que esta figura intelectual se producía: el uso de la tercera persona, la exhibición erudita de la cultura humanista, la política de citas destinada a poner al lector al corriente de la literatura especializada elaborada en los principales centros de producción internacional; estos elementos se mezclaban con una voz que, enunciada en primera persona, se involucraba en las cuestiones analizadas, ofrecía alternativas de acción y ponía de manifiesto sus esperanzas y temores en relación con ellas.

Aunque no pareciera manifestar una gran preocupación por definir los alcances de una nueva problemática teórica y por los conceptos y categorías adecuados para desplegarla (como reclamarán, poco tiempo después y en un contexto de radicalización político-intelectual, los partidarios de las nuevas ciencias de los lenguajes), la erudición desplegada por Rest y su exhibición bibliográfica bastarán para que, en un balance retrospectivo, se indique este ensayo de 1961 como uno de los precursores en la argentina de los estudios sobre cultura y medios masivos (Rivera, 1987: 71). Apoyando esta hipótesis se señala la continuidad que tomaba otro trabajo sobre la temática publicado poco tiempo después por Rest, "Alcances literarios de una dicotomía cultural" (1965). Sin embargo, una lectura atenta de ambos textos revela que, aunque sea posible establecer cierta secuencia entre ellos, en "Alcances..." Rest pone en juego un posicionamiento distinto con respecto a la cultura de masas en relación con el que había manifestado pocos años antes. Estos cambios permiten poner de relieve el modo singular en que en esta zona de saberes emergentes sobre la comunicación y la cultura se manifestaba, en el lapso que va de los inicios a mediados de los años sesenta, una "aceleración" del tiempo histórico que, como señala de manera general Carlos Altamirano (2007 [2001]: 88), produjo cambios vertiginosos en las posiciones intelectuales.

Del lado de las continuidades, el proyecto editorial de la Revista de la Universidad de la Universidad Nacional de La Plata - donde se publicaba "Alcances literarios de una dicotomía cultural" - también era producto del proceso de "normalización" institucional iniciado con el derrocamiento del peronismo. En sus inicios, la revista fundada en 1957 expresaba cierto clima de optimismo que se vivía en la unLP frente al proceso de cambio, sirviendo como uno de sus vehículos de legitimación. Sin embargo, a mediados de los

17. Sobre esta programa que combinaba humanismo y ciencias del hombre, véase el propio artículo de José Luis Romero, "Humanismo y conocimiento" (1961), publicado en el número siguiente de RUBA. 
años sesenta la publicación comenzaría a reflejar en sus páginas - y a proponer como objeto de controversia académica - ciertas tensiones en lo político, social y cultural que suscitaba el "proceso de transición". Intentaba, de este modo, ubicarse como protagonista de los debates nacionales (Suasnábar, 2004: 69).

Un indicio de ello es que, al igual que RUBA, la Revista de la Universidad había modificado su estructura, pasando a una organización temática. En este marco, dando cuenta de la existencia de un debate ya instalado en los círculos académicos, el número 19 de 1965 se dedicaba casi íntegramente a la cuestión de la cultura de masas. ${ }^{18}$ Noel Sbarra (1965: 6), director de la revista, presentaba el número refiriendo a una "irrupción de las masas en el campo de la cultura" que se hacía cada vez más perceptible por la creciente demanda de nuevos productos "a menudo tildados de 'inferiores" puestos a disposición por los "cada vez más agudizados medios de comunicación de masas". Al resultado de esta "irrupción" se la llamaba cultura de masas, por oposición a la denominada cultura elevada o cultura superior que - escribía Sbarra - "fundamentada en la noción de las humanidades modernas", sería una "cultura de 'elite' o de minorías". Que ambas coexistieran en las sociedades contemporáneas suscitaba toda una suerte de juicios y de interrogaciones sobre el destino futuro de una y otra desde distintas posiciones que incitaban a la meditación y a la discusión. Esa "labor intelectual" competía "a la condición universitaria" de la revista, afirmaba el director de la Revista de la Universidad, explicitando, de paso, el lugar que imaginaba para este proyecto editorial.

A diferencia del tono introductorio de su ensayo de 1961, en "Alcances literarios de una dicotomía cultural contemporánea"19 Rest parecía intervenir en

18. En el sumario del número encontramos artículos tanto de académicos como de productores culturales: Norberto Rodríguez Bustamante, abordaba la cuestión desde una perspectiva sociológica; Ernesto Epstein, escribía sobre música y sociedad de masas; Jorge Romero Brest, tomaba la cuestión desde el punto de vista del arte; Gregorio Weinberg, escribía sobre producción y consumo en la cultura de masas; Nicolás Babini, sobre la arquitectura de la cultura de masas; Juan Carlos Gené, sobre teatro y masas; Edmundo Eichelbaumm, sobre cine y masas.

19. Abría la serie un artículo de Norberto Rodríguez Bustamante (1965) quien se proponía ubicar las causas de la emergencia de la cultura de masas y los conflictos que desataba. La oposición e interrelación de la "cultura superior" con la cultura de masas, la influencia de ésta sobre aquella, el conflicto latente entre minorías y mayorías, los problemas de las técnicas de producción, de los objetivos, actitudes y valores que expresaban, eran presentadas por Bustamante como "las cuestiones candentes ligadas a los interrogantes básicos de nuestro tiempo" (p. 8). Menos que una pregunta en torno a las operaciones conceptuales necesarias para producir y abordar un nuevo campo de saber, su intervención revela una 
un debate ya instalado. Ahora buscaba sopesaba dos grandes posiciones respecto a la cultura de masas, aquellas que podemos definir - aunque Rest no lo hacía en estos términos - recurriendo a la oposición que no casualmente por los mismos años ofrecía y popularizaba en Italia Umberto Eco: apocalipticos versus integrados. ${ }^{20} \mathrm{~A}$ pesar de que Rest se definía en una actitud equidistante respecto de ambas posiciones (2006 [1965]: 101) dirigía su trabajo en una sola dirección polémica, esto es, hacia el "enjuiciamiento a la posición más frecuentemente reiterada en el ámbito de las humanidades tradicionales", aquella que "denunciaba" a la cultura de masas. Y no es que Rest aspirara a superar una "evaluación ambigua" de un fenómeno que - observaba - por el momento parecía inevitable; su intención era, por el contrario, "buscar cierto equilibrio estimativo" entre partidarios y críticos, puesto que la balanza por entonces se hallaba inclinada hacia éstos últimos. Rest no ahorraba ironías y duros calificativos para con las versiones pesimistas sobre la cultura de masas. Escribía:

En los últimos tiempos, la zozobra ha cundido en el mundo de las artes y de la inteligencia. Este territorio - más bien recoleto y arcádico, pese a la incesante contienda entre doctrinas, tendencias o manifiestos - se ha visto trastornado por la propagación incontenible de un supuesto flagelo que, según anuncios difundidos, pone en peligro la subsistencia misma de sus habitantes: en el baluarte exquisito y al parecer inexpugnable de la que tradicionalmente se consideró la Cultura por antonomasia ha hecho irrupción ese monstruo devorador que se llama 'masificación' (p. 93)

Entonces, si buscaba una contemporización entre posiciones que juzgaba igualmente portadoras de elementos de juicio, ¿cómo explicar esta retórica encendida que Rest dirigía hacia los detractores de la cultura de masas? ¿Se trataba sólo de volver a señalar el potencial democratizador de los medios técnicos de difusión cultural o, en un plano teórico-metodológico, el modo

profunda preocupación por contribuir desde la sociología a elaborar herramientas para la gestión de lo social. "La problemática de una cultura de masas - escribía - suscita serias cuestiones, no ya en un sentido teórico y metodológico sino, y de manera principal, al nivel de las decisiones que la práctica concertada, en función de objetivos comunes, debe resolver; pues hay ciertos nudos que sólo la acción desata" (p. 21).

20. La primera edición de Apocalittici e integratti fue publicada en 1965 en Italia por Valentino Bompiani. 
en que se cruzaban, a veces de manera productiva, la llamada alta cultura y la cultura de masas? Estos elementos sin dudas están presentes en el ensayo y marcaban elementos de continuidad con respecto al trabajo de 1961. Es más, aquí Rest profundizaba esta línea de análisis proponiendo una lectura de un corpus de "textos", algo que apenas había insinuado en su escrito anterior. No obstante, lo fundamental aquí, es de orden teórico-político: se trata de un cambio en su concepción y valoración de las masas, aquellas para las que, como vimos, no había ahorrado consideraciones negativas en su ensayo previo.

Este giro se puede seguir claramente a partir de su explicación del origen de la cultura de masas, que Rest vinculaba ahora en líneas generales y sin matices a un proceso de democratización de la vida social y cultural. $\mathrm{Si}$ bien señalaba como parte de sus causas la acción convergente de diversos factores estructurales íntimamente vinculados entre sí (la mecanización e industrialización de la producción, la ampliación del tiempo de ocio disponible, el surgimiento de un mercado consumidor, entre otros), el punto central que ponía de relieve para explicar su emergencia era un común denominador subyacente en los decisivos cambios que estaban entonces operando en la humanidad. Los definía de este modo: "una vasta marea de democratización que ha ido cobrando ímpetu en el mundo moderno y cuya consecuencia más significativa (aunque a veces epidérmica) es el acceso de los estratos más nutridos de la comunidad a beneficios que anteriormente se reservaban para círculos egregios" (pp. 95-96). Rest puntualizaba que se refería al acceso generalizado a mejores condiciones de vida material, a la ampliación del "derecho a opinar sobre asuntos de índole muy dispar", incluso a que los "gustos" de las masas eran tomados en cuenta por quienes buscaban acrecentar el consumo de la producción o encaramarse en el poder. Y si bien no era posible desconocer que este proceso entrañaba aspectos "negativos", algunos de ellos "peligros de suma gravedad", advertía, sin embargo Rest no dudaba en caracterizar los hechos en curso como un "proceso básicamente propicio y, sin lugar a dudas, irreversible que ha permitido reconocer los derechos de los sectores mayoritarios, con anterioridad marginados, y que ha patrocinado una estructuración más justa de la sociedad y una distribución más equitativa del bienestar" (p. 96).

A pesar del carácter de esta observación, que cambiaba notablemente su valoración en torno al proceso de "irrupción de las masas en la cultura", Rest no ofrecía aquí ningún tipo de referencia a la historia nacional, y mucho menos a ese fenómeno proscripto que por entonces era el peronismo. Es más, a diferencia de lo que ocurría en su ensayo anterior, prácticamente no 
hay aquí noticias del desarrollo de la cultura de masas en el país ni de los consumos o las actitudes de éstas. Por el contrario, las referencias y casos que desplegaba Rest parecían desarrollarse en una sociedad abstracta, sin un ningún anclaje particular o nacional.

Ahora bien, ¿es posible leer la caracterización que proponía Rest de la emergencia de la cultura de masas como parte de un proceso de democratización más vasto sin asociar su punto de vista a los avatares de la historia argentina o, sin eufemismos, a su posición respecto a la "cuestión peronista"? ¿Cómo leer, si no, el siguiente pasaje, donde las masas pasaban a nombrarse como sectores populares y sus críticos eran denunciados por sus actitudes conservadoras y clasistas?:

La democratización - este factor constituye la clave para interpretar la irrupción contemporánea de los sectores populares - es el hecho que los adversarios de la 'cultura de masas' han omitido prolijamente, ya sea por inadvertencia o con plena intención, con el fin de ocultar ante sí mismos y ante los demás las implicaciones político-sociales conservadoras y clasistas de su actitud (p. 97. El subrayado me pertenece).

La posición de Rest era enunciada en el marco de ciertas condiciones institucionales que trazaban el límite de lo decible; o, de otro modo, que marcaban la imposibilidad de aludir a la palabra proscripta, esto es, a la cuestión peronista. ${ }^{21}$ En este sentido, no es arriesgado observar en su ensayo una relectura de la realidad política nacional que implicaba solapadamente un reconocimiento y una revalorización del peronismo. Evidentemente, esto no suponía una novedad si se mide en relación con las actitudes de una amplia franja de intelectuales que había emprendido esta revisión inmediatamente a partir de su caída, en $1955 .{ }^{22}$ Lo destacable aquí es de otro orden. Por un lado, que esta relectura se manifestara al interior de una publicación de carácter institucional como la Revista de la Universidad de La Plata revela la existencia de tensiones existentes al interior de este espacio intelectual modernizador.

21. En relación con el peronismo como límite de lo decible para una amplia franja de la intelectualidad universitaria hacia mediados de los años sesenta, véase el trabajo de Claudia Bacci (2006), en el que analiza las intervenciones de una serie de intelectuales proveniente de diversas disciplinas en un Simposio realizado en Buenos Aires en 1966, compiladas por Rodríguez Bustamante (1967) bajo el título Los intelectuales argentinos $y$ su sociedad.

22. Ver, entre otros, Neiburg (1998) y Altamirano (2011, [2001]). 
Por otro - y esto es central para nosotros - que la emergencia del debate en torno a la cultura de masas, aunque se desplegara con un lenguaje propio, no se puede pensar como un instancia ajena a los debates político-culturales de la hora y a la progresiva radicalización de una franja intelectual, para la cual la cuestión peronista funcionaba como marco de experiencia ineludible, aunque a veces solapado. ${ }^{23}$

En el caso de Jaime Rest, su desplazamiento en torno a la cultura de masas iba de la mano de un giro respecto a su representación de la tarea intelectual. Ya la referencia en el título del parágrafo final de su ensayo a "la misión actual del humanista" nos permite leer - a modo de conclusión y de programa - un llamado a actualizar las ideas acerca de su función en relación con las demandas del presente. Esta actitud del crítico suponía una demarcación frente aquellos que, amparados en la tradición humanista clásica, se negaban a ser contemporáneos de su tiempo: si se vivía el advenimiento a un cambio profundo e irreversible, de nada valía refugiarse en imágenes del pasado y en la nostalgia del mundo pretérito: éste de ningún modo podía ser "un refugio" para evadirse de "nuestra temporalidad actual" (p. 136). El humanismo actual de Rest tenía en la mira otro tipo de humanismo, el de los "miembros egregios de las 'minorías selectas" - anotaba — que "suelen sentarse en nuestros días a llorar junto a los ríos de Babilonia, en memoria de la irrecuperable Sion". En la visión de Rest estas lamentaciones expresaban el desagrado que había originado la pérdida del "control cultural" por parte de las elites, y su negativa a intelegir el cambio era marcadamente intencional, o, de otro modo, una "resistencia a la democratización". Si para algunos intelectuales el campo de las humanidades era algo cerrado y completo, un legado estático, en la concepción de Rest el humanismo era un comportamiento dinámico y, sobre todo, "una posición de compromiso y de lucha" que se caracterizaba siempre "por la participación activa del intelectual en los problemas de su tiempo" (p. 140).

La alusión a la noción sartreana del compromiso con la que Rest llamaba a actualizar el legado humanista era explícita: el filósofo existencialista era un

23. Para el caso de la sociología, Claudio Suasnábar (2004: 72-73) propone una lectura en esta línea del artículo del sociólogo Horacio Pereyra (1965) publicado en el mismo número de la Revista de la Universidad. Radicalizando algunas posiciones de Germani desde el marxismo, Pereyra señalaba que existían tensiones inherentes al modo en que se había desplegado el proceso de modernización y desarrollo en el país, que evaluaba incompleto. Proponía entonces, aunque no aludiera en ningún momento explícitamente al peronismo, la integración de las masas a la vida política nacional en alianza con los sectores medios como modo de resolverlas. 
"verdadero precursor". Sin embargo, Rest también reunía otras referencias. Un caso reciente que expresaba esta actitud, observaba, lo ofrecía Roland Barthes, uno de los ensayistas franceses contemporáneos "de mayor lucidez y sensibilidad crítica" (p. 140) quien, en Mythologies y Essais critiques (Rest citaba ambos en sus ediciones en francés), ofrecía un modelo que contribuía al análisis de la mecánica literaria propia de la cultura de masas y al estudio de la presencia cotidiana del mito en el mundo moderno. De este modo peculiar Rest reunía la apelación al compromiso con el llamado a la actualización teórica: si no era lícito conservar "las manos limpias" para excluirse del "momento actual" y de las "responsabilidades sociales" que entrañaba la condición intelectual, era necesario también actualizar ciertas herramientas teórico-metodológicas para "introducirse en la hora presente" y actualizar el pasado cultural - señalaba - "mediante el empleo de los recursos que el mundo contemporáneo pueda proporcionarnos para tal empresa" (p. 141).

La filiación podría parecer extraña para el lector contemporáneo, teniendo en cuenta el modo en el que, muy poco tiempo después y bajo cierta impronta estructuralista, la crítica (en Francia y en sus derivas en la Argentina) dirigirá sus dardos al humanismo sartreano y se presentará, en términos de clara oposición, como su relevo. ${ }^{24}$ No obstante, Rest ofrecía aquí una mixtura en la que la tradición del compromiso del intelectual se actualizaba con el modelo que ofrecía Roland Barthes: la ampliación de los objetos de la crítica literaria hacia los de la cultura de masas en tanto operación teórico-epistemológica implicaba la búsqueda de nuevas herramientas de lectura.

\section{A MODO DE CIERRE: DEL HUMANISMO A LAS VANGUARDIAS}

Poco tiempo después de la salida del $\mathbf{N}^{\circ} 19$ de la Revista de la Universidad el golpe de Estado liderado por Onganía y su traumática intervención en la vida universitaria - una de las expresiones de lo que Oscar Terán llamará "el bloqueo tradicionalista" en la cultura y la sociedad argentinas - alterarían las coordenadas políticas del país y arrastrarían al campo académico e intelectual hacia una radicalización creciente. La publicación en 1967 a instancias de Aníbal Ford de "Alcances de una dicotomía cultural" en las ediciones del Centro Editor de América Latina (la editorial que fundará Boris Spivacow luego de abandonar EUDEBA con muchos de su colaboradores) bajo el título de Literatura y cultura de masas, que ampliará la circulación del ensayo en un

24. Para una síntesis del debate entre ambas tradiciones intelectuales en Francia, véase Descombes (1988 [1979]); para su particular expresión en la Argentina en los años sesenta, Terán (1991). 
mercado de lectores no especializados, puede ser leída como indicador de este cambio de coordenadas. En el umbral de una época, el trabajo pone de relieve la coexistencia de un perfil humanista forjado en los años de la universidad postperonista con los primeros signos de una tendencia hacia la radicalización del campo académico e intelectual. ${ }^{25}$ En el plano de los estudios en comunicación y cultura, esta se caracterizará por una serie de tópicos (que no se manifestarán de conjunto y de manera homogénea en sus principales exponentes): la revisión de los lugares desde los que se podía pensar el peronismo y la cultura popular; el supuesto de que la intervención en la cultura de masas debía ser una dimensión ineludible de la actividad intelectual; la existencia de escenarios extrauniversitarios como lugares privilegiados para su despliegue; por último, la búsqueda de una actualización teórico-metodológica que iría de la mano de una redefinición política del estatuto de los saberes científicos (la impronta althusseriana habilitaría la combinación: la pregunta por las condiciones de cientificidad estaría anudada al interrogante por la función de la ciencia en la lucha político-ideológica).

El itinerario aquí esbozado permite apreciar uno de los vectores desde los cuales entre la caída del peronismo y mediados de los años sesenta emergió investida de una doble legitimidad - científico-académica y político-intelectual - la cuestión de la cultura de masas en la Argentina. En pocos años se irán delimitando un conjunto de intervenciones que tomarán a la comunicación, los medios y la cultura como una articulación problemática y como una zona de saber a definir y legitimar, que reclamarán desde allí credenciales para la participación en los debates políticos y que promoverán la creación de espacios de producción, difusión e institucionalización especializados, ya sea en revistas, coloquios, grupos de investigación, cátedras, asociaciones o centros de investigación. A caballo entre épocas y proyectos intelectuales - que en una mirada retrospectiva podrían considerarse heterogéneos - los textos "pioneros" de Jaime Rest que aquí hemos analizado serán soslayados en los años siguientes por los representantes de las nuevas generaciones intelectuales, ávidas o bien de mayores niveles de explicitación de las operaciones teórico-metodológicas necesarias para la configuración de un nuevo campo de saber, o bien de fórmulas más explícitas para combinar esos saberes con la actividad política.

25. Radicalización a la que, por cierto, el "excéntrico" Jaime Rest no necesariamente se plegaría en todas sus manifestaciones (ver Rosa, 1987; Barduil, 1999; Crespi, 2010). Con matices, todos los críticos coinciden en señalar el descentramiento de Rest respecto a las posiciones dominantes en el campo intelectual en cada etapa de su itinerario. 


\section{BIBLIOGRAFía}

ALTAMIRANO, C. (2011 [2001]). Qué hacer con las masas, en Peronismo $y$ cultura de izquierda. Buenos Aires: Siglo XXI.

Emecé.

(2007 [2001]). Bajo el signo de las masas (1943-1973). Buenos Aires:

ARAMABURU, L.; GIORGI, G. (2013). Institucionalización y profesionalización de la sociología argentina: revisando la trayectoria de José Enrique Miguens. Nómadas. Revista Crítica de Ciencias Sociales y Jurídicas. Num. Especial: América Latina. Universidad Complutense de Madrid, Madrid, pp. 5-22.

DESCOMBES, V. (1988 [1979]). Los mismo y lo otro. Cuarenta y cinco años de filosofía francesa (1933-1978). Madrid: Cátedra.

BACCI, C. (2006). La palabra proscripta: Los intelectuales argentinos y su sociedad. Revista argentina de sociología, Año 4, número 7, Buenos Aires, pp. 134-140.

BARDAUIL, P. (1999). El excéntrico Jaime Rest, en ROSA, N. (ED.), Políticas de la crítica. Historia de la crítica literaria en la Argentina. Buenos Aires: Biblos, pp. $183-215$.

BLANCO, A. (2006). Razón y Modernidad. Gino Germani y la sociología en la Argentina. Buenos Aires: Siglo XXI.

BUSTAMANTE, N.R. (1965). "Problemática de la cultura masas", en Revista de la Universidad, Universidad Nacional de La Plata, número 19, enerodiciembre, La Plata.

CRESPI, M. (2010). De Sur a Crisis. Cuatro hipótesis sobre Jaime Rest, en REST, J., Ensayos sobre cultura y literatura nacional. Bahía Blanca: 17grises.

FORD, A. (2001 [1994]). Navegaciones. Comunicación, cultura y crisis. Buenos Aires: Amorrortu.

GERMANI, G. (1956). La integración de las masas a la vida política y el totalitarismo, Cursos y Conferencias, número 272, Buenos Aires, pp. 153-176. [Fue incluido en GERMANI, G. (1962). Política y sociedad en una época de transición. De la sociedad tradicional a la sociedad de masas. Buenos Aires: Paidós, pp. 233-252. Cito aquí la versión de BLANCO, A. (сомp.). Germani: la renovación intelectual de la sociología, Bernal: Editorial de la Universidad Nacional de Quilmes, 2006, pp. 201-221.

GRIGNON, C.; PASSERON, J-C. (1991). Lo culto y lo popular. Miserabilismo $y$ populismo en sociología y literatura. Buenos Aires: Nueva Visión.

MIGUENS, J. (1961). Un análisis del fenómeno, en AA.VV., Argentina, 19301960. Buenos Aires: Sur. 
NEIBURG, F. (1998). Los intelectuales y la invención del peronismo. Buenos Aires: Alianza.

PEREYRA, H. (1965). ¿Es la Argentina una sociedad de masas?, en Revista de la Universidad, Universidad Nacional de La Plata, número 19, enerodiciembre, La Plata.

PESCE, V. (2006). Introducción en REST, J., Arte, literatura y cultura popular. Buenos Aires: Norma.

REST, J. (1965). Alcances literarios de una dicotomía cultural contemporánea, en Revista de la Universidad, Universidad Nacional de La Plata, número 19, pp. 23-52 [reeditado en REST, J. (2006). Arte, literatura y cultura popular, Buenos Aires: Norma].

(1961). Situación del arte en la era tecnológica, en Revista de la Universidad de Buenos Aires, Quinta Época, año VI, número 2, abril-junio, pp, 297-338 [reeditado en REST, J. (2006). Arte, literatura y cultura popular, Buenos Aires: Norma].

(1960). Cuatro hipótesis de la Argentina, Bahía Blanca, Cuadernos

de Extensión Universitaria, Bahía Blanca: Universidad Nacional del Sur [reeditado en REST, J. (2010), Ensayos sobre cultura y literatura nacional, Bahía Blanca: 17grises].

RIVERA, J. (1987). La investigación en comunicación social en la Argentina, Buenos Aires: Puntosur.

ROMERO, J.L. (1961). "Humanismo y conocimiento", Revista de la Universidad de Buenos Aires, Quinta Época, Año VI, número 3, julio-setiembre, Buenos Aires.

ROSA, N. (1987). Los fulgores del simulacro, Santa Fe: Universidad del Litoral.

SAÍTTA, S. (2004). "Modos de pensar lo social. Ensayo y sociedad en la Argentina (1930-1965)”, en NEIBURG, F., PLOTKIN, M., Intelectuales y expertos. La constitución del conocimiento social en la Argentina, Buenos Aires: Paidós, pp. 107-146.

SBARRA, N. (1965). "De la Dirección", en Revista de la Universidad, Universidad Nacional de La Plata, número 19, enero-diciembre, La Plata.

SUASNÁBAR, C. (2004). Universidad en intelectuales. Educación y política en la Argentina (1955-1976), Buenos Aires: Manantial.

TERAN, O. (1991). Nuestros años sesenta, Buenos Aires: Punto Sur. 